\title{
Effectiveness of a Light Sensor for Distraction Force Measurement
}

\author{
Lili Yang*1 and Jun Cao ${ }^{2}$ \\ ${ }^{1}$ Periodontics Department, The Affiliated Stomatological hospital of Kunming Medical University, China
}

${ }^{2}$ Oral and Maxillofacial Surgery Department, The first people's hospital of Yunnan Province, China

Received: April 23, 2018; Published: April 30, 2018

*Corresponding author: Lili yang, Periodontics Department, The Affiliated Stomatological hospital of Kunming Medical University, China

Abstract

Background: Distraction osteogenesis is a biomechanical process where the application of incrementally increasing distances between living bones fragments (range of 0.5 to $1.0 \mathrm{~mm}$ per day) leads to the formation of new bone.

Objectives: The purposes of this study were twofold: (1) to evaluate the effectiveness of a light sensor in the assessment of distraction forces, and (2) to assess the accuracy of a newly-developed simple mechanism for measuring the distraction forces.

Materials and Methods: A modification of the simple mechanism was fabricated with standard loads of 10, 20 and $30 \mathrm{~N}$ to simulate the resistance of the osteotomized bone segments during distraction osteogenesis. Measurements were performed with and without the aid of a light sensor using both a modified force gauge and a UTM. Measurements were repeated 30 times for each experimental setting. A paired $t$ test was used to analyze the differences between the groups; Significance level was established at 0.01 .

Results: Significant differences were observed in all load levels between measurements with and without the light sensor for both the modified force gauge and the UTM. However, no significant difference was observed in measurements performed with the light sensor between the modified force gauge and UTM. Moreover, measurement values were significantly higher without the use of the light sensor in all groups.

Conclusions: The use of a light sensor is an effective method to aid in the precise measurement of force values. The newly-developed simple mechanism to measure the distraction forces is accurate and reliable for assessing distraction forces at different levels.

Keywords: Tension Force Measurement; Simple Mechanism; Light Sensor; UTM

\section{Introduction}

Distraction osteogenesis is a process that depends on biomechanics, a series of parameters of mechanical and biological nature that have a bearing on all distraction processes, but most of the parameters are not fully understood [1]. The traction force is one of the most important parameters during the distraction process; however, to quantify the forces necessary to distract the active reparative bone callus is a challenge [2]. Various authors have published reports on clinical or animal studies of traction force. Most of those studies were performed in long bones [3-8], or on experimental models $[2,7,9]$, with instrumented external fixators in conjunction with micrometers or goniometers $[6,10]$. In the craniofacial area, only a few studies have examined the distraction force required to lengthen the mandible or advance the maxilla. However, the measurements in most studies were performed indirectly by measurement of the torque $[2,11]$ or pressure [12] necessary to activate the distractors or by measuring and assessing bone strains.
In maxillary distraction, only a study by Suzuki and Suzuki [13] reported a simple mechanism for measuring and adjusting distraction force during maxillary distraction. According to the authors, the direct measurement of maxillary distraction force provides current information about the mechanical response, and thereby, the biomechanical changes in the distracted structures. The Suzuki mechanism was connected to the traction screws of a rigid external distraction (RED) system to permit distraction force measurement. Distraction force can be measured directly by simply pulling on the cable loop of the Suzuki mechanism. Suzuki and Suzuki suggested using an electronic light sensor to identify the minimum distance necessary to unseat the stopper of their simple mechanism. Distraction force equals the measurement that is just sufficient to unseat the stopper [13]. However, the effectiveness of the light sensor in increasing the accuracy of distraction force measurement has not been evaluated. The purposes of this study were twofold: (1) to evaluate the effectiveness of a light sensor in 
the assessment of distraction forces, and (2) to assess the accuracy of a newly-developed simple mechanism for measuring the distraction forces.

\section{Materials and Methods}

The experimental study was carried out in a custom-made spring device connected to a prototype of the Suzuki mechanism. The spring device was designed to imitate the resistance force from the surrounding tissues of the mobilized maxilla during maxillary distraction. The spring device was connected to the modification of the Suzuki mechanism. The modification of the Suzuki mechanism was similar to the device that Suzuki and Suzuki13 used on patients, except for the traction screw and anchoring tube. The modified mechanism consisted of a sliding tube and cable with a stopper at one end (Figure 1A). The spring device consisted of a PVC frame and an alloy steel spring of standard loads of $10 \mathrm{~N}, 20 \mathrm{~N}$ or $30 \mathrm{~N}$ (Figure 1B). The modification of the Suzuki mechanism was connected to the spring device with a traction cable, but the springs were inactive until measurement was begun. An electronic light sensor was applied to aid in force measurement (Figures 2A \& 2B).

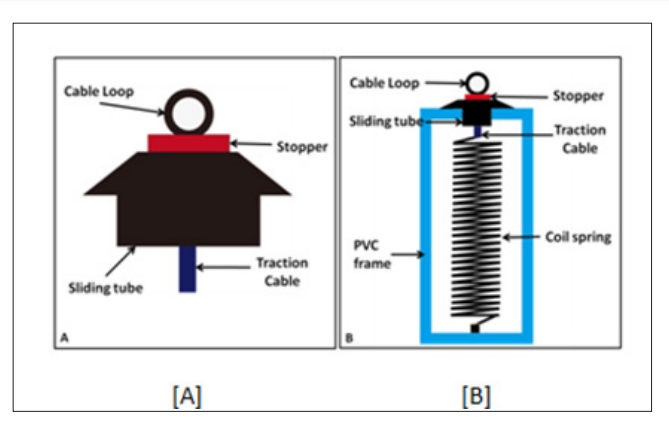

Figure 1: A modification of the Suzuki mechanism was fabricated with standard loads of 10, 20 and $30 \mathrm{~N}$ to simulate the resistance of the osteotomized bone segments during distraction osteogenesis.

A: A modification of the simple mechanism;

B: Suzuki mechanism assembled with spring device.

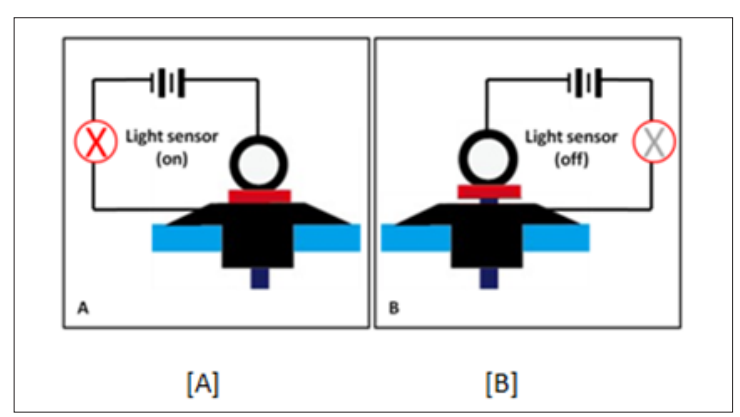

Figure 2: A light sensor was used to aid in indentifying the minimal measuring distance when the stopper just unseated from the sliding tube.

A: The light sensor turned on when the stopper was seated against the sliding tube.

B: The light sensor immediately turned off when the stopper became unseated form the sliding tube.

\section{Universal Testing Machine Measurement}

The modification of the Suzuki mechanism was assembled with the spring device and mounted on the Universal Testing Machine (UTM) (Instron 5566; Instron Corporation, London, UK) by a screw at the bottom of the spring device. The cable loop was connected to the load cell (load capacity of $100 \mathrm{~N}$ ) by a $0.9 \mathrm{~mm}$ stainless steel rigid orthodontic wire with a hook at one end. A cross-head speed of $0.5 \mathrm{~mm} / \mathrm{min}$ was used, simulating a patient applying minimal increments of lengthening.8 Measurements were performed with and without the aid of a light sensor using the UTM and repeated thirty times for each standard load of 10, 20 and $30 \mathrm{~N}$. The force values were recorded when the stopper just became unseated from the sliding tube, without the applied light sensor. When the light sensor was applied, the force values were read immediately the light sensor turned off.

\section{Force gauge measurement}

The modified force gauge was hooked onto the spring device along its long axis. Recordings of the tension forces (10, 20 and $30 \mathrm{~N}$ ) were made when the stopper was observed unseating from the sliding tube without application of the light sensor. When measuring with the light sensor, force values were recorded as soon as the light sensor turned off. Each spring load of 10, 20 and 30N was repeated thirty times by the same observer.

\section{Error Analysis}

The errors of force measurement were calculated based on the measurements of 30 cycles of each measuring method.

Dahlberg's formula14 was used to determine the measurement error. 
Dahlberg's formula14 was used to determine the measurement error:

$$
S e=\sqrt{\frac{\sum d^{2}}{2 n}}
$$

Accuracy rate and error rate were calculated using the following formulas:

Accuracy \% = (1- relative error $)$

Relative error $=($ Force gauge value-UTM value $) /$ UTM value

Error rate $=$ Measurement error $/$ UTM value $\%$

\section{Results}

Table 1: Comparison of force values measured with and without light sensor.

\begin{tabular}{|c|c|c|c|c|c|c|c|}
\hline & \multirow{2}{*}{ Load } & \multicolumn{2}{|c|}{ Without light sensor } & \multicolumn{2}{|c|}{ With light sensor } & \multirow{2}{*}{ Difference (N) } & \multirow{2}{*}{ Sig } \\
\hline & & Mean & SD & Mean & SD & & \\
\hline \multirow{3}{*}{ UTM } & $10 N$ & 10.01 & 0.03 & 9.93 & 0.02 & 0.08 & $*$ \\
\hline & $20 N$ & 20.30 & 0.02 & 20.19 & 0.01 & 0.11 & $*$ \\
\hline & $30 N$ & 30.81 & 0.02 & 30.68 & 0.01 & 0.13 & $*$ \\
\hline \multirow{3}{*}{ Force Gauge } & $10 N$ & 10.12 & 0.28 & 9.98 & 0.19 & 0.14 & $*$ \\
\hline & $20 N$ & 20.49 & 0.25 & 20.21 & 0.09 & 0.28 & $*$ \\
\hline & $30 N$ & 31.25 & 0.24 & 30.71 & 0.08 & 0.54 & $*$ \\
\hline
\end{tabular}

* $=\mathrm{P}<0.01$

Table 2: Comparison of force values measured by UTM and Force gauge.

\begin{tabular}{|c|c|c|c|c|c|c|c|}
\hline & \multirow{2}{*}{ Load } & \multicolumn{2}{|c|}{ UTM } & \multicolumn{2}{|c|}{ Force Gauge } & \multirow{2}{*}{ Difference (N) } & \multirow{2}{*}{ Sig } \\
\hline & & Mean & SD & Mean & SD & & \\
\hline \multirow{3}{*}{$\begin{array}{l}\text { Without light } \\
\text { sensor }\end{array}$} & $10 \mathrm{~N}$ & 10.01 & 0.03 & 10.12 & 0.28 & 0.11 & $*$ \\
\hline & $20 \mathrm{~N}$ & 20.30 & 0.02 & 20.49 & 0.25 & 0.19 & $*$ \\
\hline & $30 \mathrm{~N}$ & 30.81 & 0.02 & 31.25 & 0.24 & 0.44 & $*$ \\
\hline \multirow{3}{*}{$\begin{array}{l}\text { With light } \\
\text { sensor }\end{array}$} & $10 \mathrm{~N}$ & 9.93 & 0.02 & 9.98 & 0.19 & 0.05 & NS \\
\hline & $20 \mathrm{~N}$ & 20.19 & 0.01 & 20.21 & 0.09 & 0.02 & NS \\
\hline & $30 \mathrm{~N}$ & 30.68 & 0.01 & 30.71 & 0.08 & 0.03 & NS \\
\hline
\end{tabular}

$*=\mathrm{P}<0.01, \mathrm{NS}=$ No significant different

Table 3: The accuracy rate, measurement error and error rate in different load levels.

\begin{tabular}{|c|c|c|c|c|}
\hline \multirow{3}{*}{ Load } & Accuracy Rate (\%) & Measurement Error (N) & Error Rate (\%) \\
\cline { 2 - 5 } & & Mean \pm SD & Mean \pm SD & Mean \pm SD \\
\hline \multirow{3}{*}{ Without light sensor } & $10 \mathrm{~N}$ & $98.95 \pm 1.55 \mathrm{a}$ & $0.0136 \pm 0.0202 \mathrm{a}$ & $0.14 \pm 0.20 \mathrm{~b}$ \\
\cline { 2 - 5 } & $20 \mathrm{~N}$ & $99.04 \pm 1.06 \mathrm{~b}$ & $0.0252 \pm 0.0277 \mathrm{a}$ & $0.12 \pm 0.14 \mathrm{a}$ \\
\cline { 2 - 5 } & $30 \mathrm{~N}$ & $98.56 \pm 0.73 \mathrm{ab}$ & $0.0571 \pm 0.029 \mathrm{~b}$ & $0.19 \pm 0.09 \mathrm{ab}$ \\
\cline { 2 - 5 } With light sensor & $10 \mathrm{~N}$ & $99.52 \pm 0.78 \mathrm{a}$ & $0.0062 \pm 0.0101 \mathrm{~b}$ & $0.06 \pm 0.10 \mathrm{~b}$ \\
\cline { 2 - 5 } & $20 \mathrm{~N}$ & $99.87 \pm 0.30 \mathrm{~b}$ & $0.0033 \pm 0.0077 \mathrm{a}$ & $0.02 \pm 0.04 \mathrm{a}$ \\
\cline { 2 - 5 } & $30 \mathrm{~N}$ & $99.90 \pm 0.18 \mathrm{~b}$ & $0.0041 \pm 0.0070 \mathrm{a}$ & $0.01 \pm 0.02 \mathrm{a}$ \\
\hline
\end{tabular}

Note: ab Different superscripts within a row are significantly different from each other at $a=0.01$ as determined by Tukey's post hoc test.

The averages of tension force measured by the UTM without the light sensor were $10.01 \pm 0.03 \mathrm{~N}, 20.30 \pm 0.02 \mathrm{~N}$ and $30.81 \pm 0.02 \mathrm{~N}$ for spring loads of 10,20 and $30 \mathrm{~N}$, respectively. These averages were accepted as the standard reference values to compare with the averages of tension force measured by the force gauge, which were $10.12 \pm 0.28 \mathrm{~N}, 20.49 \pm 0.25 \mathrm{~N}$, and $31.25 \pm 0.24 \mathrm{~N}$, respectively. Significant differences were observed at all load levels between measurements performed with and without the light sensor for both the modified force gauge and the UTM (Table 1). The averages of tension force measured by the UTM with the light sensor were $9.93 \pm 0.02 \mathrm{~N}, 20.19 \pm 0.01 \mathrm{~N}$ and $30.68 \pm 0.01 \mathrm{~N}$, respectively; those measured by the force gauge with the light sensor were $0.98 \pm$ $0.19 \mathrm{~N}, 20.21 \pm 0.09 \mathrm{~N}$ and $30.71 \pm 0.08 \mathrm{~N}$, respectively. No significant difference was observed between measurements performed with 
the light sensor between the modified force gauge and UTM. Moreover, measurement values were significantly higher without the use of the light sensor at each experimental setting (Table 2). The measurement errors were very small and the accuracy rate was high at each setting. The accuracy rates with the light sensor were significantly higher than without. And there were significant differences in measurement error and accuracy rate between different loads level (Table 3).

\section{Discussion}

This study shows that a light sensor is an effective method for the precise measurement of force values and that the newly-developed simple mechanism to measure the distraction forces is accurate and reliable for assessing distraction forces at different levels. Distraction osteogenesis is a process that depends on biomechanics [1]. The distraction force is one of the most important parameters during the distraction process [2]. All investigators agree that the clinical assessment of distraction forces is an important tool for the clinician to better understand the biomechanical response of the distracted structures and to manage the symptoms [1-6]. Therefore, accuracy and reliability are very important in assessing the distraction force. The light sensor is effective in increasing the accuracy and reliability of distraction force measurement through identifying the minimal measuring distance between the stopper and sliding tube [13], a feature which is difficult to observe by visual inspection during clinical measurement.

The distraction structures may be influenced if the stopper is pulled too much from the tube, the measuring distance should be less than the activation distance. The results of examining the ratio between the actual maxillary distraction and the distraction of the rigid external distraction device (RED system) used for maxillary distraction in patients with a cleft deformity have shown that, the ratio of device activation to skeletal movement is not 1:1 $[15,16]$. The amount of skeletal movement is less than the amount of device activation. And the most commonly used distraction rate is 0.5 to $1 \mathrm{~mm}$ per day [17]. For the above reasons, the measuring distance should be less than $0.5 \mathrm{~mm}$ to prevent the distraction structures being influenced. However, during the measurement of clinical distraction, it is difficult to observe the "small" distance by visual inspection. Therefore, using a light sensor to identify the minimal necessary measuring distance that just unseats the stopper from the sliding tube is an important factor in distraction force measurement.

In this study, significantly different force values were observed with and without the light sensor whether measured by the UTM or the modified force gauge. And the force values measured without the light sensor were significantly higher than those with the light sensor. Based on Hooke's law, we know that the higher force values without the light sensor are due to the more stretched distance of the spring that equals the distance between the stopper and sliding tube. The measured distance without the light sensor is greater than that with the light sensor, which is an unacceptable result during distraction force measurement. Thus the light sensor is effective in identifying the minimal measuring distance, increasing the accuracy and reliability of force measurement as suggested by Suzuki and Suzuki [13]. In the study, the force values were not significantly different between UTM and the modified force gauge when measuring with light sensor.

The study proved that the simple mechanism with the light sensor is accurate in measuring distraction force. In contrast, there was a difference between the two devices when measurements were made without the light sensor. The accuracy rate of measurements with the light sensor was significantly higher than without the light sensor; this also proved that the Suzuki mechanism is accurate and reliable for measuring distraction force. The study proved the effectiveness of the light sensor and the accuracy of the Suzuki mechanism, which will help to accurately measure the force values during the distraction process and to adjust the force level in order to optimize the distraction procedure and to decrease patient discomfort and symptoms. Significant differences were observed between different load levels. At high load levels, the force measurements showed greater accuracy rates and lower error rates than at low load levels. However, the differences were within clinically acceptable limits. Possible reasons may be that the sensitivity of the light sensor has more influence when measuring low force levels. This possibility needs further study to assess the sensitivity of the light sensor in measuring distances at different force levels.

\section{Conclusion}

The use of a light sensor is an effective method to aid in the precise measurement of force values. A newly-developed simple mechanism to measure distraction forces is accurate and reliable for assessing distraction forces at different levels.

\section{Acknowledgment}

The authors acknowledge the assistance of Dr M. K. Kevin O. Carroll, professor emeritus of the University of Mississippi School of Dentistry, and faculty consultant of the Chiang Mai University Faculty of Dentistry, Thailand, in the preparation of the manuscript.

\section{References}

1. Forriol F, Goenaga I, Mora G, Vinolas J, Canadell J (1997) Measurement of bone lengthening forces; an experimental model in the lamb. Clin Biomech 12(1): 17-21.

2. Robinson RC, O’Neal PJ, Robinson GH (2001) Mandibular distraction force: laboratory data and clinical correlation. J Oral Maxillofac Surg 59(5): 539-544.

3. Jones CB, Dewar ME, Aichroth PM, Crawfurd EJ, Emery R (1989) Epiphyseal distraction monitored by strain gauges. Results in seven children. J Bone Joint Surg Br 71: 651-656.

4. Kenwright J, Spriggins AJ, Cunningham JL (1990) Response of the growth plate to distraction close to skeletal maturity. Is fracture necessary? Clin Orthop Relat Res 250:61-72.

5. van Roermund PM, Wijlens RA, Renooij W (1992) Continuous monitoring of forces during tibial lengthening by distraction epiphysiolysis. Acta Orthop Belg 58: 63-68.

6. Aronson J, Harp JH (1994) Mechanical forces as predictors of healing during tibial lengthening by distraction osteogenesis. Clin Orthop Relat Res 301: 73-79. 
7. Brunner UH, Cordey J, Schweiberer L, Perren SM (1994) Force required for bone segment transport in the treatment of large bone defects using medullary nail fixation. Clin Orthop Relat Res 301: 147-155.

8. Gardner TN, Evans M, Simpson AH, Kyberd PJ, Kenwright J (1997) A method of examining the magnitude and origin of "soft" and "hard" tissue forces resisting limb lengthening. Med Eng Phys 19: 405-411.

9. Herford AS, Finn R, Tharanon W, Sinn DP (2000) Tension forces in relation to LeFort III osteotomies. J Craniofac Surg 11(2): 197-202.

10. Richardson JB, Cunningham JL, Goodship AE, O'Connor BT, Kenwright J (1994) Measuring stiffness can define healing of tibial fractures. J Bone Joint Surg Br 76(3): 389-394.

11. Burstein FD, Lukas S, Forsthoffer D (2008) Measurement of torque during mandibular distraction. J Craniofac Surg 19(3): 644-647.

12. Wiltfang J, Kessler P, Merten HA, Neukam FW (2001) Continuous and intermittent bone distraction using a microhydraulic cylinder: an experimental study in minipigs. Br J Oral Maxillofac Surg 39: 2-7.
13. Suzuki EY, Suzuki B (2009) A simple mechanism for measuring and adjusting distraction forces during maxillary advancement. J Oral Maxillofac Surg 67(10): 2245-2253

14. Houston WJ (1983) The analysis of errors in orthodontic measurements. Am J Orthod 83(5): 382-390.

15. Block MS, Cervini D, Chang A, Gottsegen GB (1995) Anterior maxillary advancement using tooth-supported distraction osteogenesis. J Oral Maxillofac Surg 53(5): 561-565.

16. Harada K, Sato M, Omura K (2004) Maxillary distraction in patients with cleft deformity using a rigid external distraction device: a pilot study on the distraction ratio of the maxilla to the device. Scand J Plast Reconstr Surg Hand Surg 38(5): 277-280.

17. Saltaji H, Major MP, Altalibi M, Youssef M, Flores-Mir C (2012) Longterm skeletal stability after maxillary advancement with distraction osteogenesis in cleft lip and palate patients. Angle orthod 82(6): 11151122 .

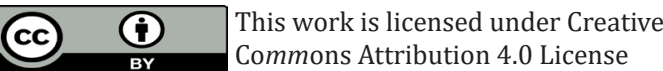

Submission Link: https://biomedres.us/submit-manuscript.php

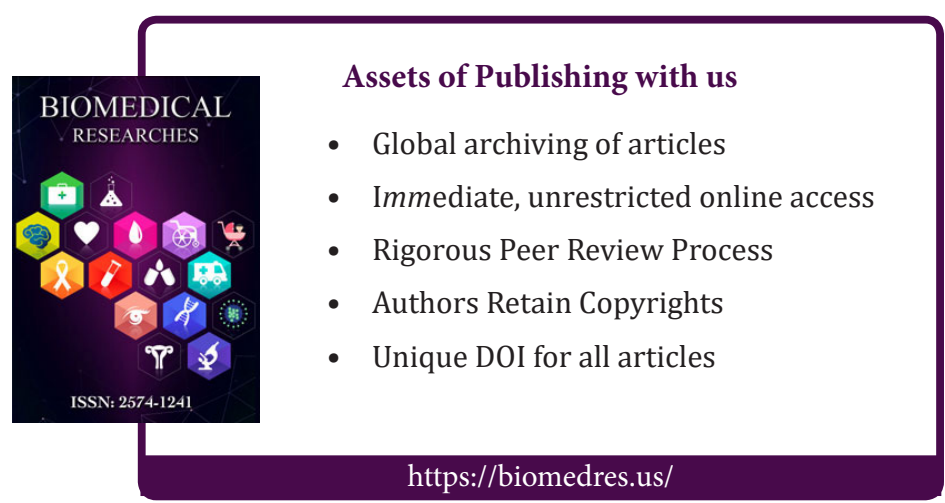

